\title{
Some coincidence theorems for generalized nonlinear contractions in ordered metric spaces with applications
}

\author{
Aftab Alam', Abdur Rauf Khan² and Mohammad Imdad ${ }^{1 *}$
}

"Correspondence:

mhimdad@yahoo.co.in

'Department of Mathematics,

Aligarh Muslim University, Aligarh,

202002, India

Full list of author information is

available at the end of the article

\begin{abstract}
In this article, we prove some existence and uniqueness results on coincidence points for $g$-increasing mappings satisfying generalized $\varphi$-contractivity conditions in ordered metric spaces. As an application of one of our newly proved results, we indicate the formulation of a coupled coincidence theorem. Our results generalize, extend, modify, improve, sharpen, enrich, and complement several well-known results of the existing literature. Also, we point out that a recent coincidence point result proved in Dalal et al. (J. Adv. Math. 7(1):1084-1094, 2014) contains errors and omissions.
\end{abstract}

MSC: $47 \mathrm{H} 10 ; 54 \mathrm{H} 25$

Keywords: ordered metric spaces; $g$-monotone mappings; $M C B$ property; O-compatible pair; generalized $\varphi$-contractions

\section{Introduction}

In 2004, Ran and Reurings [1] extended the Banach contraction principle in ordered metric spaces for continuous monotone mappings with some applications to matrix equations wherein the involved contractive condition is required to hold merely on elements which are comparable in the underlying partial ordering. Thereafter, Nieto and Rodríguez-López [2] slightly modified Ran and Reurings' fixed point theorem for an increasing mapping not necessarily continuous by assuming an additional hypothesis on the ordered metric space and also proved some related results on ordered metric spaces besides giving some applications to ordinary differential equations. In the same development, Nieto and RodríguezLópez [3] analogously proved a fixed point theorem for a decreasing mapping in ordered metric space and also gave some applications of their results to ordinary differential equations. In recent years, Nieto and Rodríguez-López's ( $c f$. [2]) fixed point theorems were further extended and refined by many authors (e.g. [4-17]).

The idea of the coupled fixed point was initiated by Guo and Lakshmikantham [18] in 1987, which was well followed by Bhaskar and Lakshmikantham [19] where the authors introduced the notion of mixed monotone property for a linear contraction (mapping) $F$ : $X^{2} \rightarrow X$ (wherein $X$ is an ordered metric space) and utilized the same to prove some theorems on the existence and uniqueness of coupled fixed points, which can also be viewed as a coupled formulation of certain results of Nieto and Rodríguez-López [2]. In 2009, Lakshmikantham and Ćirić [20] generalized these results for nonlinear contraction mappings by introducing the notions of coupled coincidence point and mixed $g$-monotone property. In

C2014 Alam et al.; licensee Springer. This is an Open Access article distributed under the terms of the Creative Commons Attribution License (http://creativecommons.org/licenses/by/2.0), which permits unrestricted use, distribution, and reproduction in any medium, provided the original work is properly cited. 
recent years, the existence results on coupled fixed points were generalized and improved by various authors (e.g. [21-27]). Very recently, Samet et al. [28] have shown that the coupled fixed results can be more easily obtained using well-known fixed point theorems on ordered metric spaces (see also [29-31]). For further details, one can consult [32-40].

The aim of this paper is four-fold:

(1) We observe that a $\varphi$-contraction indicated in Boyd and Wong [41] (later used by Jotić [42]) generalizes several well-known $\varphi$-contractions due to Browder [43], Mukherjea [44], Lakshmikantham and Ćirić [20] and similar others.

(2) We extend some fixed point results of Nieto and Rodríguez-López [2] to a pair $(f, g)$ of mappings such that $f$ is $g$-increasing mapping satisfying generalized nonlinear contractive condition of Boyd and Wong [41] on an ordered metric space $X$ in two different directions namely: in case $X$ is complete or alternately one of the subspaces $f(X)$ or $g(X)$ is complete while the whole space $X$ may or may not be complete. Some illustrative examples are also furnished to demonstrate our results.

(3) Following the techniques of Samet et al. [28], we indicate a coupled coincidence theorem which can be obtained as an application of our newly established result.

(4) We consolidate several weaker results on ordered metric spaces (especially those obtained in Nieto and Rodríguez-López [2], Wu and Liu [17], Radenović [29], Al-Mezel et al. [30], Ćirić et al. [6], Dalal et al. [31], Choudhury and Kundu [21], Hussain et al. [22] and Sintunavarat and Kumam [23]) besides correcting errors in a recent coincidence point result proved in Dalal et al. [31].

\section{Preliminaries}

In this section, to make our exposition self contained, we recall some basic definitions, relevant notions and auxiliary results:

Definition 1 [45] A relation $\preceq$ defined on a nonempty set $X$ is called a partial order on $X$ if it is reflexive, antisymmetric and transitive. A set $X$ together with a partial order $\preceq$, often denoted by $(X, \preceq)$, is called an ordered set. Let $(X, \preceq)$ be an ordered set and $x, y \in X$. Then the statement

$$
x \preceq y \text { is read as ' } x \text { precedes } y \text { '. }
$$

Analogously, we also write:

$x \prec y$ means $x \preceq y$ and $x \neq y$, which is read ' $x$ strictly precedes $y$ ',

$x \succeq y$ means $y \preceq x$, which is read ' $x$ succeeds $y$ ',

$x \succ y$ means $y \prec x$, which is read ' $x$ strictly succeeds $y$ '.

As usual, the notations $\npreceq, \nprec, \nsucceq$ and $\nsucc$ are self-explanatory.

Definition $2[45]$ Let $(X, \preceq)$ be an ordered set and $x, y \in X$. We say that $x$ and $y$ are comparable if either $x \preceq y$ or $x \succeq y$. For brevity, we denote it by $x \prec \succ y$.

Remark 1 [13] The relation $\prec \succ$ is reflexive and symmetric, but not transitive in general.

Definition 3 [45] Let $(X, \preceq)$ be an ordered set. A subset $E \subseteq X$ is called totally or linearly ordered if every pair of elements of $E$ are comparable, i.e.,

$$
x \prec \succ y \quad \forall x, y \in E .
$$


Definition 4 [45] Let $(X, \preceq)$ be an ordered set and $E \subseteq X$. An element $u \in X$ is called an upper bound of $E$ if $u$ succeeds every element of $E$, i.e.,

$$
x \preceq u \quad \forall x \in E .
$$

Analogously, an element $l \in X$ is called a lower bound of $E$ if $l$ precedes every element of E, i.e.,

$$
x \succeq l \quad \forall x \in E .
$$

Definition 5 [5] A triplet $(X, d, \preceq)$ is called an ordered metric space if $(X, d)$ is a metric space and $(X, \preceq)$ is an ordered set.

Definition 6 [46-51] Let $(X, \preceq)$ be an ordered set and $f$ a self mapping on $X$. We say that

(i) $f$ is increasing or isotone or order-preserving if for any $x, y \in X$

$$
x \preceq y \quad \Rightarrow \quad f(x) \preceq f(y),
$$

(ii) $f$ is decreasing or antitone or order-reversing if for any $x, y \in X$

$$
x \preceq y \quad \Rightarrow \quad f(x) \succeq f(y),
$$

(iii) $f$ is monotone if it is either increasing or decreasing.

Definition 7 [6] Let $(X, \preceq)$ be an ordered set and $f$ and $g$ a pair of self mappings on $X$. We say that

(i) $f$ is $g$-increasing if for any $x, y \in X$

$$
g(x) \preceq g(y) \quad \Rightarrow \quad f(x) \preceq f(y),
$$

(ii) $f$ is $g$-decreasing if for any $x, y \in X$

$$
g(x) \preceq g(y) \quad \Rightarrow \quad f(x) \succeq f(y),
$$

(iii) $f$ is $g$-monotone if $f$ is either $g$-increasing or $g$-decreasing.

Notice that under the restriction $g=I$, the identity mapping on $X$, Definition 7 reduces to Definition 6.

Proposition 1 Let $f$ and $g$ be a pair of self mappings defined on an ordered set $(X, \preceq)$. Iff is $g$-monotone and $g(x)=g(y)$, then $f(x)=f(y)$.

Proof As $g(x)=g(y)$, on using reflexivity of $\preceq$, we have

$$
g(x) \preceq g(y) \text { and } \quad g(x) \succeq g(y) .
$$

Suppose that $f$ is $g$-increasing (resp. $g$-decreasing), we have

$$
f(x) \preceq f(y) \quad \text { and } \quad f(x) \succeq f(y) \quad(\text { resp. } f(x) \succeq f(y) \text { and } f(x) \preceq f(y)) \text {, }
$$


which, in both cases (owing to the antisymmetric property of $\preceq$ ) gives rise to

$$
f(x)=f(y) .
$$

Definition 8 [52] Let $(X, \preceq)$ be an ordered set. A sequence $\left\{x_{n}\right\}$ in $X$ is said to be

(i) increasing or ascending if for any $m, n \in \mathbb{N} \cup\{0\}$,

$$
m \leq n \quad \Rightarrow \quad x_{m} \preceq x_{n},
$$

(ii) decreasing or descending if for any $m, n \in \mathbb{N} \cup\{0\}$,

$$
m \leq n \quad \Rightarrow \quad x_{m} \geq x_{n}
$$

(iii) monotone if it is either increasing or decreasing,

(iv) bounded above if there is an element $u \in X$ such that

$$
x_{n} \preceq u \quad \forall n \in \mathbb{N} \cup\{0\},
$$

so that $u$ is an upper bound of $\left\{x_{n}\right\}$,

(v) bounded below if there is an element $l \in X$ such that

$$
x_{n} \succeq l \quad \forall n \in \mathbb{N} \cup\{0\},
$$

so that $l$ is a lower bound of $\left\{x_{n}\right\}$.

Definition $9[53,54]$ Let $X$ be a nonempty set and $f$ and $g$ two self mappings on $X$. Then

(i) an element $x \in X$ is called a coincidence point of $f$ and $g$ if

$$
g(x)=f(x)
$$

(ii) if $x \in X$ is a coincidence point of $f$ and $g$ and $\bar{x} \in X$ such that $\bar{x}=g(x)=f(x)$, then $\bar{x}$ is called a point of coincidence of $f$ and $g$,

(iii) if $x \in X$ is a coincidence point of $f$ and $g$ such that $x=g(x)=f(x)$, then $x$ is called a common fixed point of $f$ and $g$,

(iv) the pair $(f, g)$ is said to be commuting if

$$
g(f x)=f(g x) \quad \forall x \in X
$$

(v) the pair $(f, g)$ is said to be weakly compatible or coincidentally commuting if $f$ and $g$ commute at their coincidence points, i.e.,

$$
g(f x)=f(g x) \quad \text { whenever } g(x)=f(x) .
$$

Further, for the sake of brevity, we record the following fact in the form of a proposition:

Proposition 2 If the pair $(f, g)$ is weakly compatible, then every point of coincidence of $f$ and $g$ is also a coincidence point of $f$ and $g$. 
Proof Let $\bar{x}$ be a point of coincidence of $f$ and $g$, then $\exists x \in X$ such that $\bar{x}=g(x)=f(x)$. Now, we have to show that $\bar{x}$ is a coincidence point of $f$ and $g$. On using the weak compatibility of $f$ and $g$, we have

$$
g(\bar{x})=g(f x)=f(g x)=f(\bar{x})
$$

which implies that $\bar{x}$ is a coincidence point of $f$ and $g$.

Definition $10[55,56]$ Let $(X, d)$ be a metric space and $f$ and $g$ two self mappings on $X$. Then

(i) the pair $(f, g)$ is said to be weakly commuting if

$$
d(g f x, f g x) \leq d(g x, f x)
$$

(ii) the pair $(f, g)$ is said to be compatible if

$$
\lim _{n \rightarrow \infty} d\left(g f x_{n}, f g x_{n}\right)=0
$$

whenever $\left\{x_{n}\right\}$ is a sequence in $X$ such that

$$
\lim _{n \rightarrow \infty} g\left(x_{n}\right)=\lim _{n \rightarrow \infty} f\left(x_{n}\right)
$$

Definition $11[30,57]$ Let $(X, d, \preceq)$ be an ordered metric space and $f$ and $g$ two self mappings on $X$. We say that the pair $(f, g)$ is $O$-compatible if

$$
\lim _{n \rightarrow \infty} d\left(g f x_{n}, f g x_{n}\right)=0
$$

whenever $\left\{x_{n}\right\}$ is a sequence in $X$ such that $\left\{g x_{n}\right\}$ is monotone and

$$
\lim _{n \rightarrow \infty} g\left(x_{n}\right)=\lim _{n \rightarrow \infty} f\left(x_{n}\right)
$$

Evidently, in an ordered metric space, commutativity $\Rightarrow$ weak commutativity $\Rightarrow$ compatibility $\Rightarrow O$-compatibility $\Rightarrow$ weak compatibility but reverse implications are not true in general as substantiated by the following examples.

Example 1 [55] Consider $X=[0,1]$ with the usual metric. Define the functions $f: X \rightarrow X$ and $g: X \rightarrow X$ by $f(x)=\frac{x}{2}$ and $g(x)=\frac{x}{2}+x \forall x \in X$. Then the pair $(f, g)$ is weakly commutative but not commutative.

Example 2 [56] Consider $X=\mathbb{R}$ with the usual metric. Define the functions $f: X \rightarrow X$ and $g: X \rightarrow X$ by $f(x)=x^{3}$ and $g(x)=2 x^{3} \forall x \in X$. Then the pair $(f, g)$ is compatible but not weakly commutative.

Example 3 [57] Consider $X=\{0\} \cup\left[\frac{1}{2}, 2\right]$ with the usual metric and the following partial order:

$$
x, y \in X, \quad x \preceq y \quad \Leftrightarrow \quad x=y \quad \text { or } \quad(x, y) \in\{(0,0),(0,1),(1,1)\} .
$$


Define the functions $f: X \rightarrow X$ and $g: X \rightarrow X$ by

$$
f(x)= \begin{cases}0 & \text { if } x \in\{0\} \cup\left[\frac{1}{2}, 1\right] \\ 1 & \text { otherwise }\end{cases}
$$

and

$$
g(x)= \begin{cases}0 & \text { if } x=0 \\ 1 & \text { if } \frac{1}{2} \leq x \leq 1 \\ 2-x & \text { if } 1<x \leq \frac{3}{2} \\ \frac{1}{2} & \text { if } \frac{3}{2}<x \leq 2\end{cases}
$$

Then the pair $(f, g)$ is $O$-compatible but not compatible.

Example 4 Consider $X=[1,7]$ with the usual metric and the usual partial order. Define the functions $f: X \rightarrow X$ and $g: X \rightarrow X$ by

$$
f(x)= \begin{cases}1 & \text { if } x=1 \text { or } x \in(3,7] \\ 5 & \text { if } x \in(1,3]\end{cases}
$$

and

$$
g(x)= \begin{cases}x & \text { if } x \in[1,3], \\ x-2 & \text { if } x \in(3,7] .\end{cases}
$$

Here 1 is the only coincidence point of $f$ and $g$ and $\mathrm{f}(\mathrm{g} 1)=\mathrm{g}(\mathrm{fl})=1$. Therefore $(f, g)$ is a weakly compatible pair.

Consider a sequence $\left\{x_{n}\right\} \subset X$, where $x_{n}=3+\frac{1}{n} \forall n \in \mathbb{N}$ then $f\left(x_{n}\right)=1$ and $g\left(x_{n}\right)=1+\frac{1}{n}$. Hence $\left\{g x_{n}\right\}$ is decreasing and $\lim _{n \rightarrow \infty} g\left(x_{n}\right)=\lim _{n \rightarrow \infty} f\left(x_{n}\right)=1$. Also, $f\left(g x_{n}\right)=f\left(1+\frac{1}{n}\right)=5$ and $g\left(f x_{n}\right)=g(1)=1$, which implies that $\lim _{n \rightarrow \infty} d\left(g f x_{n}, f g x_{n}\right)=4 \neq 0$. It follows that the pair $(f, g)$ is not $O$-compatible.

Let $(X, d, \preceq)$ be an ordered metric space and $\left\{x_{n}\right\} \subset X$. We adopt the following notations:

(i) if $\left\{x_{n}\right\}$ is increasing and $x_{n} \stackrel{d}{\rightarrow} x$ then we denote it symbolically by $x_{n} \uparrow x$,

(ii) if $\left\{x_{n}\right\}$ is decreasing and $x_{n} \stackrel{d}{\rightarrow} x$ then we denote it symbolically by $x_{n} \downarrow x$.

In the following lines, we formulate some definitions using certain properties utilized by earlier authors especially from $[2,6,19,20]$ besides some other ones.

Definition 12 Let $(X, d, \preceq)$ be an ordered metric space. We say that

(i) $(X, d, \preceq$ ) has the ICU (increasing-convergence-upper bound) property if every increasing convergent sequence $\left\{x_{n}\right\}$ in $X$ is bounded above by its limit (as an upper bound), i.e.,

$$
x_{n} \uparrow x \Rightarrow x_{n} \preceq x \quad \forall n \in \mathbb{N} \cup\{0\},
$$


(ii) $(X, d, \preceq)$ has the $D C L$ (decreasing-convergence-lower bound) property if every decreasing convergent sequence $\left\{x_{n}\right\}$ in $X$ is bounded below by its limit (as a lower bound), i.e.,

$$
x_{n} \downarrow x \quad \Rightarrow \quad x_{n} \succeq x \quad \forall n \in \mathbb{N} \cup\{0\},
$$

(iii) $(X, d, \preceq$ ) has the $M C B$ (monotone-convergence-boundedness) property if $X$ has the $I C U$ as well as the $D C L$ property.

Remark 2 It is warranted to mention that the terminologies utilized in Definition 12 are available under different names as adopted by various authors in their respective papers. Instead of saying that $X$ has the ICU property, alternately Turinici [58] said that $(\preceq)$ is $d$-self-closed, Jleli et al. [15] said that $X$ is regular and Kutbi et al. [59] said that $X$ is nondecreasing-regular. Similarly, instead of saying that $X$ has the $D C L$ property, alternately Turinici [58] said that $(\succeq)$ is $d$-self-closed and Kutbi et al. [59] said that $X$ is nonincreasing-regular. Also, instead of saying that $X$ has the $M C B$ property, alternately Jleli et al. [15] said that $X$ is $\uparrow \downarrow$-regular, Berzig and Samet [60] said that $X$ is regular and Roldan et al. [61] said that $X$ has sequential monotone property.

Definition 13 Let $(X, d, \preceq)$ be an ordered metric space and $g$ a self mapping on $X$. We say that

(i) $(X, d, \preceq)$ has the $g$-ICU property if $g$-image of every increasing convergent sequence $\left\{x_{n}\right\}$ in $X$ is bounded above by $g$-image of its limit (as an upper bound), i.e.,

$$
x_{n} \uparrow x \Rightarrow g\left(x_{n}\right) \preceq g(x) \quad \forall n \in \mathbb{N} \cup\{0\},
$$

(ii) $(X, d, \preceq)$ has the $g$-DCL property if $g$-image of every decreasing convergent sequence $\left\{x_{n}\right\}$ in $X$ is bounded below by $g$-image of its limit (as a lower bound), i.e.,

$$
x_{n} \downarrow x \quad \Rightarrow \quad g\left(x_{n}\right) \succeq g(x) \quad \forall n \in \mathbb{N} \cup\{0\},
$$

(iii) $(X, d, \preceq)$ has the $g-M C B$ property if it has the $g$-ICU as well as the $g$ - $D C L$ property. Notice that under the restriction $g=I$, the identity mapping on $X$, Definition 13 reduces to Definition 12.

Now, we summarize some basic definitions related to coupled coincidence points.

Definition 14 [20] Let $(X, \preceq)$ be an ordered set and $F: X^{2} \rightarrow X$ and $g: X \rightarrow X$ two mappings. We say that $F$ has the mixed $g$-monotone property if $F$ is $g$-increasing in its first argument and is $g$-decreasing in its second argument, i.e., for all $x, y \in X$,

$$
\begin{array}{ll}
x_{1}, x_{2} \in X, & g\left(x_{1}\right) \preceq g\left(x_{2}\right) \quad \Rightarrow \quad F\left(x_{1}, y\right) \preceq F\left(x_{2}, y\right), \\
y_{1}, y_{2} \in X, & g\left(y_{1}\right) \preceq g\left(y_{2}\right) \quad \Rightarrow \quad F\left(x, y_{1}\right) \succeq F\left(x, y_{2}\right) .
\end{array}
$$

Notice that under the restriction $g=I$, the identity mapping on $X$, Definition 14 reduces to the definition of mixed monotone property of $F$. 
Definition 15 [20] Let $X$ be a nonempty set and $F: X^{2} \rightarrow X$ and $g: X \rightarrow X$ two mappings. An element $(x, y) \in X^{2}$ is called a coupled coincidence point of mappings $F$ and $g$ if

$$
F(x, y)=g(x), \quad F(y, x)=g(y) .
$$

Notice that under the restriction $g=I$, the identity mapping on $X,(x, y)$ is called a coupled fixed point of $F$.

Definition 16 [20] Let $X$ be a nonempty set and $F: X^{2} \rightarrow X$ and $g: X \rightarrow X$ two mappings. We say that the pair $(F, g)$ is commuting if

$$
g(F(x, y))=F(g x, g y) \quad \forall x, y \in X .
$$

Definition 17 [21] Let $(X, d)$ be a metric space and $F: X^{2} \rightarrow X$ and $g: X \rightarrow X$ two mappings. We say that the pair $(F, g)$ is compatible if

$$
\lim _{n \rightarrow \infty} d\left(g F\left(x_{n}, y_{n}\right), F\left(g x_{n}, g y_{n}\right)\right)=0
$$

and

$$
\lim _{n \rightarrow \infty} d\left(g F\left(y_{n}, x_{n}\right), F\left(g y_{n}, g x_{n}\right)\right)=0,
$$

whenever $\left\{x_{n}\right\}$ and $\left\{y_{n}\right\}$ are sequences in $X$ such that

$$
\lim _{n \rightarrow \infty} F\left(x_{n}, y_{n}\right)=\lim _{n \rightarrow \infty} g\left(x_{n}\right) \text { and } \lim _{n \rightarrow \infty} F\left(y_{n}, x_{n}\right)=\lim _{n \rightarrow \infty} g\left(y_{n}\right) .
$$

Definition 18 [57] Let $(X, d, \preceq)$ be an ordered metric space and $F: X^{2} \rightarrow X$ and $g: X \rightarrow X$ two mappings. We say that the pair $(F, g)$ is $O$-compatible if

$$
\lim _{n \rightarrow \infty} d\left(g F\left(x_{n}, y_{n}\right), F\left(g x_{n}, g y_{n}\right)\right)=0
$$

and

$$
\lim _{n \rightarrow \infty} d\left(g F\left(y_{n}, x_{n}\right), F\left(g y_{n}, g x_{n}\right)\right)=0,
$$

whenever $\left\{x_{n}\right\}$ and $\left\{y_{n}\right\}$ are sequences in $X$ such that $\left\{g x_{n}\right\},\left\{g y_{n}\right\}$ are monotone and

$$
\lim _{n \rightarrow \infty} F\left(x_{n}, y_{n}\right)=\lim _{n \rightarrow \infty} g\left(x_{n}\right) \text { and } \lim _{n \rightarrow \infty} F\left(y_{n}, x_{n}\right)=\lim _{n \rightarrow \infty} g\left(y_{n}\right) .
$$

Finally, we list the following known results needed in the proof of our main results.

Lemma 1 [11] Let $(X, d)$ be a metric space and $\left\{x_{n}\right\}$ a sequence in $X$ such that $\lim _{n \rightarrow \infty} d\left(x_{n}\right.$, $\left.x_{n+1}\right)=0$. If $\left\{x_{n}\right\}$ is not a Cauchy sequence, then there exist $\epsilon>0$ and two subsequences $\left\{x_{n_{k}}\right\}$ and $\left\{x_{m_{k}}\right\}$ of $\left\{x_{n}\right\}$ such that

(i) $n_{k}>m_{k} \geq k$

(ii) $d\left(x_{m_{k}}, x_{n_{k}}\right) \geq \epsilon$, 
(iii) $d\left(x_{m_{k}}, x_{n_{k}-1}\right)<\epsilon$,

(iv) the following four sequences tend to $\epsilon$ when $k \rightarrow \infty$ :

$$
d\left(x_{m_{k}}, x_{n_{k}}\right), \quad d\left(x_{m_{k}+1}, x_{n_{k}}\right), \quad d\left(x_{m_{k}}, x_{n_{k}+1}\right), \quad d\left(x_{m_{k}+1}, x_{n_{k}+1}\right) .
$$

Lemma 2 [62] Let $X$ be a nonempty set and $g$ a self mapping on $X$. Then there exists a subset $E \subseteq X$ such that $g(E)=g(X)$ and $g: E \rightarrow X$ is one-to-one.

\section{Existing control functions and possible inter-relations}

Recall that a self mapping $f$ defined on a metric space $(X, d)$ satisfying

$$
d(T x, T y) \leq \alpha d(x, y) \quad \forall x, y \in X
$$

where $\alpha \in[0,1)$ is a constant, is called a linear contraction with respect to $\alpha$ (or, in short, $\alpha$-contraction). In view of the classical Banach contraction principle [63], every linear contraction defined on a complete metric space admits a unique fixed point. Here it can be noticed that the non-negative constant $\alpha<1$ plays a key role. Many authors generalized the Banach contraction principle by replacing the involved constant $\alpha$ with an appropriate mapping, say $\varphi$, depending on the contractivity condition. A function $\varphi:[0, \infty) \rightarrow[0, \infty)$ satisfying $\varphi(t)<t$ for each $t>0$ is called a control function. Further, a self mapping $f$ defined on a metric space $(X, d)$ is called a nonlinear contraction with respect to control function $\varphi$ (or, in short, $\varphi$-contraction) if

$$
d(f x, f y) \leq \varphi(d(x, y)) \quad \forall x, y \in X
$$

Indeed for each $\alpha \in[0,1)$, on setting $\varphi(t)=\alpha t, \varphi$-contraction reduces to $\alpha$-contraction. In fact, in 1968, Browder [43] initiated the notion of $\varphi$-contraction, where the author assumed $\varphi$ to be a right continuous and increasing control function and utilized the same to generalize the Banach contraction principle. Later, many authors generalized Browder's fixed point theorem by varying the properties of control function $\varphi$. In 1969, Boyd and Wong [41] observed that it is sufficient to assume merely the right-upper semicontinuity of $\varphi$ (without the monotonicity requirement on $\varphi$ ) and extended Browder's fixed point theorem by introducing the following family of control functions:

$$
\begin{aligned}
\Psi= & \{\varphi:[0, \infty) \rightarrow[0, \infty): \varphi(t)<t \text { for each } t>0 \text { and } \\
& \varphi \text { is right-upper semicontinuous }\} .
\end{aligned}
$$

Inspired by Boyd and Wong [41], in 1977, Mukherjea [44] slightly modified Browder's fixed point theorem by introducing the following family of control functions:

$$
\Theta=\{\varphi:[0, \infty) \rightarrow[0, \infty): \varphi(t)<t \text { for each } t>0 \text { and } \varphi \text { is right continuous }\} .
$$

The following family of control functions found in literature is more natural:

$$
\mathfrak{\Im}=\{\varphi:[0, \infty) \rightarrow[0, \infty): \varphi(t)<t \text { for each } t>0 \text { and } \varphi \text { is continuous }\}
$$


The following family of control functions is introduced by Lakshmikantham and Ćirić [20]:

$$
\Phi=\left\{\varphi:[0, \infty) \rightarrow[0, \infty): \varphi(t)<t \text { for each } t>0 \text { and } \lim _{r \rightarrow t^{+}} \varphi(r)<t \text { for each } t>0\right\} .
$$

The following family of control functions is indicated in Boyd and Wong [41] but was later used by Jotić [42]:

$$
\Omega=\left\{\varphi:[0, \infty) \rightarrow[0, \infty): \varphi(t)<t \text { for each } t>0 \text { and } \limsup _{r \rightarrow t^{+}} \varphi(r)<t \text { for each } t>0\right\} .
$$

The following properties of control functions are needed in the subsequent discussion.

\section{Proposition 3 Let $\varphi$ be a control function.}

(a) If $\varphi$ is right continuous, then $\lim _{r \rightarrow t^{+}} \varphi(r)<t$ for each $t>0$.

(b) If $\varphi$ is right-upper semicontinuous, then $\lim \sup _{r \rightarrow t^{+}} \varphi(r)<t$ for each $t>0$.

Proof To prove (a), take an arbitrary $t>0$. As $\varphi$ is right continuous on $[0, \infty)$, therefore in particular at $t$, we have

$$
\lim _{r \rightarrow t^{+}} \varphi(r)=\varphi(t) .
$$

As $\varphi$ is control function, we have

$$
\varphi(t)<t
$$

Hence (1) and (2) implies that $\lim _{r \rightarrow t^{+}} \varphi(r)<t$. As $t>0$ is arbitrary, we have

$$
\lim _{r \rightarrow t^{+}} \varphi(r)<t \quad \text { for each } t>0 .
$$

In a similar manner we can prove (b). For an arbitrary $t>0$, using right-upper semicontinuity of $\varphi$, we have $\lim \sup _{r \rightarrow t^{+}} \varphi(r) \leq \varphi(t)$, which on using $\varphi(t)<t$ implies that $\lim \sup _{r \rightarrow t^{+}} \varphi(r)<t$ for each $t>0$.

Now, we present our main result of this section as follows:

Proposition 4 The class $\Omega$ enlarges the classes $\Psi, \Theta, \Im$ I and $\Phi$.

Proof On using the fact that continuity implies right continuity and right continuity implies right-upper semicontinuity together with item (b) of Proposition 3, we have

$$
\Im \subset \Theta \subset \Psi \subset \Omega .
$$

It is obvious that $\Phi \subset \Omega$. Also on using item (a) of Proposition 3, we have $\Theta \subset \Phi$. Hence, on combining these relations, we have

$$
\Im \subset \Theta \subset \Phi \subset \Omega .
$$


Hence from (3) and (4), it follows that $\Omega$ enlarges the rest of all the above families of control functions.

The following property of $\varphi \in \Omega$ in the form of a lemma is used in our main results.

Lemma 3 Let $\varphi \in \Omega$. If $\left\{a_{n}\right\} \subset(0, \infty)$ is a sequence such that $a_{n+1} \leq \varphi\left(a_{n}\right) \forall n \in \mathbb{N} \cup\{0\}$, then $\lim _{n \rightarrow \infty} a_{n}=0$.

Proof Given that

$$
a_{n+1} \leq \varphi\left(a_{n}\right) \quad \forall n \in \mathbb{N} \cup\{0\} .
$$

As $a_{n}>0$, on using (5) and the definition of $\Omega$, we have

$$
a_{n+1}<a_{n} \quad \forall n \in \mathbb{N} \cup\{0\},
$$

so that $\left\{a_{n}\right\}$ is a decreasing sequence of positive real numbers. Since it is bounded below (as $a_{n}>0$ ), there is an element $a \geq 0$ such that

$$
\lim _{n \rightarrow \infty} a_{n}=a .
$$

Our proof is complete if we show that $a=0$. Suppose, on the contrary that $a>0$. Taking the limit superior as $n \rightarrow \infty$ of both sides of (5) and using (6) and the definition of $\Omega$, we have

$$
a=\limsup _{n \rightarrow \infty} a_{n+1} \leq \limsup _{n \rightarrow \infty} \varphi\left(a_{n}\right)=\limsup _{a_{n} \rightarrow a^{+}} \varphi\left(a_{n}\right)<a,
$$

which is a contradiction, so that $a=0$.

\section{Results on coincidence points}

We prove one of our main results as follows:

Theorem 1 Let $(X, d, \preceq)$ be an ordered metric space and $f$ and $g$ two self mappings on $X$. Suppose that the following conditions hold:

(a) $f(X) \subseteq g(X)$,

(b) $f$ is $g$-increasing,

(c) there exists $x_{0} \in X$ such that $g\left(x_{0}\right) \preceq f\left(x_{0}\right)$,

(d) there exists $\varphi \in \Omega$ such that

$$
d(f x, f y) \leq \varphi(d(g x, g y)) \quad \forall x, y \in X \text { with } g(x) \prec \succ g(y),
$$

(e) (e1) $(X, d)$ is complete,

(e2) $(f, g)$ is O-compatible pair,

(e3) $g$ is continuous,

(e4) either $f$ is continuous or $(X, d, \preceq)$ has the g-ICU property,

or alternately 
$\left(\mathrm{e}^{\prime}\right)\left(\mathrm{e}^{\prime} 1\right)$ either $(g X, d)$ or $(f X, d)$ is complete,

$\left(\mathrm{e}^{\prime} 2\right)$ either $f$ and $g$ are continuous or $(g X, d, \preceq)$ has the ICU property.

Then $f$ and $g$ have a coincidence point.

Proof In view of assumption (d), the contractivity condition $d(f x, f y) \leq \varphi(d(g x, g y))$ holds for any $x, y \in X$ under two possibilities:

either $\quad g(x) \preceq g(y)$ or $\quad g(x) \succeq g(y)$.

If our contractivity condition is satisfied for first possibility, then in view of symmetry of $d$, it must be satisfied for the second possibility and vice versa. Therefore on imposing our contractivity condition these two possibilities are equivalent and hence we use only the first possibility to prove our result.

In view of assumption (c) if $g\left(x_{0}\right)=f\left(x_{0}\right)$, then $x_{0}$ is a coincidence point of $f$ and $g$ and hence the proof is completed. Otherwise, if $g\left(x_{0}\right) \neq f\left(x_{0}\right)$, then we have $g\left(x_{0}\right) \prec f\left(x_{0}\right)$. So in view of (a) (i.e. $f X \subseteq g X$ ), we can choose $x_{1} \in X$ such that $g\left(x_{1}\right)=f\left(x_{0}\right)$. As $f(X) \subseteq g(X)$, we can choose $x_{2} \in X$ such that $g\left(x_{2}\right)=f\left(x_{1}\right)$. Continuing this process, we define a sequence $\left\{x_{n}\right\} \subset X$ (of joint iterates) such that

$$
g\left(x_{n+1}\right)=f\left(x_{n}\right) \quad \forall n \in \mathbb{N} \cup\{0\} .
$$

Now, we assert that $\left\{g x_{n}\right\}$ is an increasing sequence, i.e.,

$$
g\left(x_{n}\right) \preceq g\left(x_{n+1}\right) \quad \forall n \in \mathbb{N} \cup\{0\} .
$$

We prove this fact by mathematical induction. On using (7) with $n=0$ and assumption (c), we have

$$
g\left(x_{0}\right) \preceq f\left(x_{0}\right)=g\left(x_{1}\right) .
$$

Thus, (8) holds for $n=0$. Suppose that (8) holds for $n=r>0$, i.e.,

$$
g\left(x_{r}\right) \preceq g\left(x_{r+1}\right),
$$

then we have to show that (8) holds for $n=r+1$. To accomplish this, we use (7), (9), and assumption (b), so that

$$
g\left(x_{r+1}\right)=f\left(x_{r}\right) \preceq f\left(x_{r+1}\right)=g\left(x_{r+2}\right) .
$$

Thus, by induction, (8) holds for all $n \in \mathbb{N} \cup\{0\}$.

If $g\left(x_{n_{0}}\right)=g\left(x_{n_{0}+1}\right)$ for some $n_{0} \in \mathbb{N}$, then using (7), we have $g\left(x_{n_{0}}\right)=f\left(x_{n_{0}}\right)$, i.e., $x_{n_{0}}$ is a coincidence point of $f$ and $g$, so that we are through. On the other hand, if $g\left(x_{n}\right) \neq g\left(x_{n+1}\right)$ for each $n \in \mathbb{N} \cup\{0\}$, we can define a sequence $\left\{d_{n}\right\}_{n=0}^{\infty} \subset(0, \infty)$, where

$$
d_{n}:=d\left(g x_{n}, g x_{n+1}\right)
$$


On using (7), (8), (10), and assumption (d), we obtain

$$
\begin{aligned}
d_{n+1} & =d\left(g x_{n+1}, g x_{n+2}\right) \\
& =d\left(f x_{n}, f x_{n+1}\right) \\
& \leq \varphi\left(d\left(g x_{n}, g x_{n+1}\right)\right) \\
& =\varphi\left(d_{n}\right),
\end{aligned}
$$

so that

$$
d_{n+1} \leq \varphi\left(d_{n}\right)
$$

Hence by Lemma 3, we obtain

$$
\lim _{n \rightarrow \infty} d_{n}=\lim _{n \rightarrow \infty} d\left(g x_{n}, g x_{n+1}\right)=0 .
$$

Next, we show that $\left\{g x_{n}\right\}$ is a Cauchy sequence. On the contrary suppose that $\left\{g x_{n}\right\}$ is not a Cauchy sequence. Hence, in view of (11) and Lemma 1, there exists $\epsilon>0$ and two subsequences $\left\{g x_{n_{k}}\right\}$ and $\left\{g x_{m_{k}}\right\}$ of $\left\{g x_{n}\right\}$ such that $n_{k}>m_{k} \geq k, d\left(g x_{m_{k}}, g x_{n_{k}}\right) \geq \epsilon$, $d\left(g x_{m_{k}}, g x_{n_{k}-1}\right)<\epsilon$ and

$$
\begin{aligned}
\lim _{k \rightarrow \infty} d\left(g x_{m_{k}}, g x_{n_{k}}\right) & =\lim _{k \rightarrow \infty} d\left(g x_{m_{k}+1}, g x_{n_{k}}\right) \\
& =\lim _{k \rightarrow \infty} d\left(g x_{m_{k}}, g x_{n_{k}+1}\right) \\
& =\lim _{k \rightarrow \infty} d\left(g x_{m_{k}+1}, g x_{n_{k}+1}\right)=\epsilon .
\end{aligned}
$$

Denote $r_{k}:=d\left(g x_{m_{k}}, g x_{n_{k}}\right)$. As $m_{k}<n_{k}$, due to (8) we have $g\left(x_{m_{k}}\right) \preceq g\left(x_{n_{k}}\right)$. On using (7) and assumption (d), we obtain

$$
\begin{aligned}
d\left(g x_{m_{k}+1}, g x_{n_{k}+1}\right) & =d\left(f x_{m_{k}}, f x_{n_{k}}\right) \\
& \leq \varphi\left(d\left(g x_{m_{k}}, g x_{n_{k}}\right)\right) \\
& =\varphi\left(r_{k}\right),
\end{aligned}
$$

so that

$$
d\left(g x_{m_{k}+1}, g x_{n_{k}+1}\right) \leq \varphi\left(r_{k}\right) .
$$

On taking the limit superior as $k \rightarrow \infty$ in (13) and using (12) and the definition of $\Omega$, we have

$$
\epsilon=\limsup _{k \rightarrow \infty} d\left(g x_{m_{k}+1}, g x_{n_{k}+1}\right) \leq \limsup _{k \rightarrow \infty} \varphi\left(r_{k}\right)=\limsup _{r_{k} \rightarrow \epsilon^{+}} \varphi\left(r_{k}\right)<\epsilon
$$

which is a contradiction. Therefore $\left\{g x_{n}\right\}$ is a Cauchy sequence. Now, we use assumptions (e) or (e') to accomplish the proof. 
Firstly, assume that (e) holds. By assumption (e1) (i.e. completeness of $X$ ), there exists $z \in X$ such that

$$
\lim _{n \rightarrow \infty} g\left(x_{n}\right)=z
$$

On using (7) and (14), we obtain

$$
\lim _{n \rightarrow \infty} f\left(x_{n}\right)=\lim _{n \rightarrow \infty} g\left(x_{n+1}\right)=z .
$$

In view of assumption (e3) (i.e. continuity of $g$ ) in (14) and (15), we have

$$
\begin{aligned}
& \lim _{n \rightarrow \infty} g\left(g x_{n}\right)=g\left(\lim _{n \rightarrow \infty} g x_{n}\right)=g(z), \\
& \lim _{n \rightarrow \infty} g\left(f x_{n}\right)=g\left(\lim _{n \rightarrow \infty} f x_{n}\right)=g(z) .
\end{aligned}
$$

As $\left\{g x_{n}\right\}$ is monotone (due to (8)) and $\lim _{n \rightarrow \infty} f\left(x_{n}\right)=\lim _{n \rightarrow \infty} g\left(x_{n}\right)=z$ (due to (14) and (15)), on using assumption (e2) (i.e. O-compatibility of $f$ and $g$ ), we obtain

$$
\lim _{n \rightarrow \infty} d\left(g f x_{n}, f g x_{n}\right)=0 .
$$

Now, we show that $z$ is a coincidence point of $f$ and $g$. To accomplish this, we use assumption (e4). Suppose that $f$ is continuous. On using (14) and the continuity of $f$, we obtain

$$
\lim _{n \rightarrow \infty} f\left(g x_{n}\right)=f\left(\lim _{n \rightarrow \infty} g x_{n}\right)=f(z) .
$$

On using (17), (18), (19), and the continuity of $d$, we obtain

$$
\begin{aligned}
d(g z, f z) & =d\left(\lim _{n \rightarrow \infty} g f x_{n}, \lim _{n \rightarrow \infty} f g x_{n}\right) \\
& =\lim _{n \rightarrow \infty} d\left(g f x_{n}, f g x_{n}\right) \\
& =0,
\end{aligned}
$$

so that

$$
g(z)=f(z)
$$

Thus $z \in X$ is a coincidence point of $f$ and $g$ and hence we are through.

Alternately, suppose that $(X, d, \preceq)$ has the $g-I C U$ property. Due to (8) and (14), we have $g\left(x_{n}\right) \uparrow z$, which gives rise

$$
g\left(g x_{n}\right) \preceq g(z) \quad \forall n \in \mathbb{N} \cup\{0\} .
$$

On using (20) and assumption (d), we obtain

$$
d\left(f g x_{n}, f z\right) \leq \varphi\left(d\left(g g x_{n}, g z\right)\right) \quad \forall n \in \mathbb{N} \cup\{0\} .
$$

Now, we assert that

$$
d\left(f g x_{n}, f z\right) \leq d\left(g g x_{n}, g z\right) \quad \forall n \in \mathbb{N} .
$$


On account of the two different possibilities arising here, we consider a partition $\left\{\mathbb{N}^{0}, \mathbb{N}^{+}\right\}$ of $\mathbb{N}$, i.e., $\mathbb{N}^{0} \cup \mathbb{N}^{+}=\mathbb{N}$ and $\mathbb{N}^{0} \cap \mathbb{N}^{+}=\emptyset$ verifying that

(i) $d\left(g g x_{n}, g z\right)=0 \forall n \in \mathbb{N}^{0}$,

(ii) $d\left(g g x_{n}, g z\right)>0 \forall n \in \mathbb{N}^{+}$.

In case (i), on using Proposition 1, we get $d\left(f g x_{n}, f z\right)=0 \forall n \in \mathbb{N}^{0}$ and hence (21) holds for all $n \in \mathbb{N}^{0}$. In case (ii), owing to the definition of $\Omega$, we have $d\left(f g x_{n}, f z\right) \leq \varphi\left(d\left(g g x_{n}, g z\right)\right)<$ $d\left(g g x_{n}, g z\right) \forall n \in \mathbb{N}^{+}$and hence (21) holds for all $n \in \mathbb{N}^{+}$. Thus (21) holds for all $n \in \mathbb{N}$.

On using triangular inequality, (16), (17), (18), and (21), we get

$$
\begin{aligned}
d(g z, f z) & \leq d\left(g z, g f x_{n}\right)+d\left(g f x_{n}, f g x_{n}\right)+d\left(f g x_{n}, f z\right) \\
& \leq d\left(g z, g f x_{n}\right)+d\left(g f x_{n}, f g x_{n}\right)+d\left(g g x_{n}, g z\right) \\
& \rightarrow 0 \quad \text { as } n \rightarrow \infty,
\end{aligned}
$$

so that

$$
g(z)=f(z) .
$$

Thus $z \in X$ is a coincidence point of $f$ and $g$ and hence we are through.

Secondly, assume that ( $\left.\mathrm{e}^{\prime}\right)$ holds. In view of assumption ( $\left.\mathrm{e}^{\prime} 1\right)$, firstly we assume that $g(X)$ is complete, then there exists $u \in X$ such that

$$
\lim _{n \rightarrow \infty} g\left(x_{n}\right)=g(u)
$$

Alternately, if $f(X)$ is complete, then in view of (7), we have $f\left(x_{n}\right)=g\left(x_{n+1}\right) \forall n \in \mathbb{N} \cup\{0\}$, so that $\left\{f x_{n}\right\}$ is a Cauchy sequence in $f(X)$. Hence, on using the completeness of $f(X)$ and assumption (a) (i.e., $f(X) \subseteq g(X)$ ), there exists $u \in X$ such that

$$
\lim _{n \rightarrow \infty} g\left(x_{n+1}\right)=\lim _{n \rightarrow \infty} f\left(x_{n}\right)=g(u) .
$$

Thus, in both cases, we have

$$
\lim _{n \rightarrow \infty} g\left(x_{n}\right)=g(u), \quad u \in X .
$$

Now, we show that $u$ is a coincidence point of $f$ and $g$. To accomplish this, we use assumption (e'2). Suppose that $f$ and $g$ are continuous. Owing to Lemma 2, there exists a subset $E \subseteq X$ such that $g(E)=g(X)$ and $g: E \rightarrow X$ is one-one. Without loss of generality, we are able to choose $E \subseteq X$ such that $u \in E$. Now, define $T: g(E) \rightarrow g(X)$ by

$$
T(g e)=f(e) \quad \forall g(e) \in g(E) \text {, where } e \in E .
$$

As $g: E \rightarrow X$ is one-one and $f(X) \subseteq g(X), T$ is well defined. Again since $f$ and $g$ are continuous, it follows that $T$ is continuous. Since $\left\{x_{n}\right\} \subset X$ and $g(X)=g(E)$, there exists $\left\{e_{n}\right\} \subset E$ such that $g\left(x_{n}\right)=g\left(e_{n}\right) \forall n \in \mathbb{N} \cup\{0\}$. By using Proposition 1, we get $f\left(x_{n}\right)=f\left(e_{n}\right)$ $\forall n \in \mathbb{N} \cup\{0\}$. Therefore, on using (7) and (22), we get

$$
\lim _{n \rightarrow \infty} g\left(e_{n}\right)=\lim _{n \rightarrow \infty} f\left(e_{n}\right)=g(u) .
$$


On using (23), (24), and the continuity of $T$, we get

$$
f(u)=T(g u)=T\left(\lim _{n \rightarrow \infty} g e_{n}\right)=\lim _{n \rightarrow \infty} T\left(g e_{n}\right)=\lim _{n \rightarrow \infty} f\left(e_{n}\right)=g(u) .
$$

Thus $u \in X$ is a coincidence point of $f$ and $g$ and hence we are done.

Otherwise, suppose that $(g X, d, \preceq)$ has the $I C U$ property. Due to (8) and (22), we have $g\left(x_{n}\right) \uparrow g(u)$, which gives rise

$$
g\left(x_{n}\right) \preceq g(u) \quad \forall n \in \mathbb{N} \cup\{0\} .
$$

On using (7), (25), and assumption (d), we obtain

$$
d\left(g x_{n+1}, f u\right)=d\left(f x_{n}, f u\right) \leq \varphi\left(d\left(g x_{n}, g u\right)\right) \quad \forall n \in \mathbb{N} \cup\{0\}
$$

We assert that

$$
d\left(g x_{n+1}, f u\right) \leq d\left(g x_{n}, g u\right) \quad \forall n \in \mathbb{N} .
$$

On account of the two different possibilities arising here, we consider a partition $\left\{\mathbb{N}^{0}, \mathbb{N}^{+}\right\}$ of $\mathbb{N}$, i.e., $\mathbb{N}^{0} \cup \mathbb{N}^{+}=\mathbb{N}$ and $\mathbb{N}^{0} \cap \mathbb{N}^{+}=\emptyset$ verifying that

(i) $d\left(g x_{n}, g u\right)=0 \forall n \in \mathbb{N}^{0}$,

(ii) $d\left(g x_{n}, g u\right)>0 \forall n \in \mathbb{N}^{+}$.

In case (i), on using Proposition 1, we get $d\left(f x_{n}, f u\right)=0 \forall n \in \mathbb{N}^{0}$, which in view of (7), gives rise $d\left(g x_{n+1}, f u\right)=0 \forall n \in \mathbb{N}^{0}$ and hence (26) holds for all $n \in \mathbb{N}^{0}$. In case (ii), by the definition of $\Omega$, we have $d\left(g x_{n+1}, f u\right) \leq \varphi\left(d\left(g x_{n}, g u\right)\right)<d\left(g x_{n}, g u\right) \forall n \in \mathbb{N}^{+}$and hence (26) holds for all $n \in \mathbb{N}^{+}$. Thus (26) holds for all $n \in \mathbb{N}$.

On using (22), (26), and the continuity of $d$, we get

$$
\begin{aligned}
d(g u, f u) & =d\left(\lim _{n \rightarrow \infty} g x_{n+1}, f u\right) \\
& =\lim _{n \rightarrow \infty} d\left(g x_{n+1}, f u\right) \\
& \leq \lim _{n \rightarrow \infty} d\left(g x_{n}, g u\right) \\
& =0,
\end{aligned}
$$

so that

$$
g(u)=f(u)
$$

Hence $u \in X$ is a coincidence point of $f$ and $g$. This completes the proof.

Corollary 1 If in addition to the hypotheses (a)-(d) of Theorem 1, one of the following conditions holds:

(f) (f1) $(X, d)$ is complete,

(f2) either $f$ or $g$ is onto,

(f3) either $f$ and $g$ are continuous or $(g X, d, \preceq)$ has the ICU property;

$\left(\mathrm{f}^{\prime}\right)\left(\mathrm{f}^{\prime} 1\right)(X, d)$ is complete,

$\left(f^{\prime} 2\right)$ either $f(X)$ or $g(X)$ is closed, 
( $\left.f^{\prime} 3\right)$ either $f$ and $g$ are continuous or $(g X, d, \preceq)$ has the ICU property;

$\left(\mathrm{f}^{\prime \prime}\right)\left(\mathrm{f}^{\prime \prime} 1\right) \quad(X, d)$ is complete,

$\left(\mathrm{f}^{\prime \prime} 2\right)(f, g)$ is O-compatible pair,

$\left(\mathrm{f}^{\prime \prime} 3\right) \mathrm{g}$ is continuous and increasing,

$\left(\mathrm{f}^{\prime \prime} 4\right)(X, d, \preceq)$ has the ICU property,

then $f$ and $g$ have a coincidence point.

Proof Suppose that (f) hold. By (f2), we get either $f(X)=X$ or $g(X)=X$, so that (f1) implies that either $f(X)$ or $g(X)$ is complete and hence assumption $\left(\mathrm{e}^{\prime}\right)$ is applicable.

Suppose that $\left(\mathrm{f}^{\prime}\right)$ hold. We know that closed subset of a complete metric space is complete. It follows, from $\left(\mathrm{f}^{\prime} 1\right)$ and $\left(\mathrm{f}^{\prime} 2\right)$, that either $f(X)$ or $g(X)$ is complete and hence assumption $\left(\mathrm{e}^{\prime}\right)$ is applicable.

Suppose that $\left(\mathrm{f}^{\prime \prime}\right)$ hold. Now $g$ is increasing and $(X, d, \preceq)$ has the $I C U$ property, this implies that $(X, d, \preceq)$ has the $g$-ICU property. Hence, in this case, assumption (e) is applicable.

Next, we present a result dual to Theorem 1 .

Theorem 2 Theorem 1 remains true if we replace conditions (c), (e4), and ( $\left.\mathrm{e}^{\prime} 2\right)$ by the conditions (c)', (e4)' and $\left(\mathrm{e}^{\prime} 2\right)^{\prime}$, respectively (besides retaining the rest of the hypotheses):

(c)' there exists $x_{0} \in X$ such that $g\left(x_{0}\right) \succeq f\left(x_{0}\right)$,

(e4)' either $f$ is continuous or $(X, d, \preceq)$ has the $g$-DCL property,

$\left(\mathrm{e}^{\prime} 2\right)^{\prime}$ either $f$ and $g$ are continuous or $(g X, d, \preceq)$ has the DCL property.

Proof The scheme of the proof is similar to the one followed in the proof of Theorem 1. Following the lines of the proof of Theorem 1, we can show that the sequence $\left\{g x_{n}\right\}$ is decreasing and also Cauchy.

Assume that (e) holds. The completeness of $X$ implies the existence of $z \in X$ such that $g\left(x_{n}\right) \stackrel{d}{\rightarrow} z$ as $n \rightarrow \infty$. To prove $z \in X$ is a coincidence point of $f$ and $g$, firstly we suppose that $f$ is continuous. In this case, following the lines of the proof of Theorem 1 , we can show that $f(z)=g(z)$. Otherwise suppose that $(X, d, \preceq)$ has the $g$-DCL property, so analogously as in (20), we have

$$
g\left(g x_{n}\right) \succeq g(z) \quad \forall n \in \mathbb{N} \cup\{0\}
$$

and hence proceeding along the lines of the proof of Theorem 1, the result can be proved.

On the other hand, assume that ( $\left.\mathrm{e}^{\prime}\right)$ holds. The completeness of $g(X)$ or $f(X)$ implies the existence of $u \in X$ such that $g\left(x_{n}\right) \stackrel{d}{\rightarrow} g(u)$ as $n \rightarrow \infty$. To prove that $u \in X$ is a coincidence point of $f$ and $g$, firstly we suppose that $f$ and $g$ are continuous, then as argued in Theorem 1, we can show that $f(u)=g(u)$. Otherwise suppose that $(g X, d, \preceq)$ has the $D C L$ property, so analogously as in (25), we have

$$
g\left(x_{n}\right) \succeq g(u) \quad \forall n \in \mathbb{N} \cup\{0\}
$$

and hence proceeding along the lines of the proof of Theorem 1, the result can be proved.

On combining Theorem 1 and Theorem 2, we obtain the following result. 
Theorem 3 Let $(X, d, \preceq)$ be an ordered metric space and $f$ and $g$ two self mappings on $X$. Suppose that the following conditions hold:

(a) $f(X) \subseteq g(X)$,

(b) $f$ is g-increasing,

(c) there exists $x_{0} \in X$ such that $g\left(x_{0}\right) \prec \succ f\left(x_{0}\right)$,

(d) there exists $\varphi \in \Omega$ such that

$$
d(f x, f y) \leq \varphi(d(g x, g y)) \quad \forall x, y \in X \text { with } g(x) \prec \succ g(y),
$$

(e) (e1) $(X, d)$ is complete,

(e2) $(f, g)$ is O-compatible pair,

(e3) $g$ is continuous,

(e4) either $f$ is continuous or $(X, d, \preceq)$ has the $g$-MCB property,

or alternately

( $\left.\mathrm{e}^{\prime}\right)\left(\mathrm{e}^{\prime} 1\right)$ either $(g X, d)$ or $(f X, d)$ is complete,

$\left(\mathrm{e}^{\prime} 2\right)$ either $f$ and $g$ are continuous or $(g X, d, \preceq)$ has the MCB property.

Then $f$ and $g$ have a coincidence point.

Analogously, we can prove results similar to Corollary 1 corresponding to Theorems 2 and 3.

As commutativity $\Rightarrow$ weak commutativity $\Rightarrow$ compatibility $\Rightarrow O$-compatibility for a pair of mappings, the following consequence of Theorem 1 (also of Theorem 2 or Theorem 3) trivially holds.

Corollary 2 Theorem 1 (also Theorem 2 or Theorem 3 ) remains true if we replace condition (e2) by one of the following conditions (besides retaining the rest of the hypotheses):

$(\mathrm{e} 2)^{\prime} \quad(f, g)$ is commuting pair,

$(\mathrm{e} 2)^{\prime \prime}(f, g)$ is weakly commuting pair,

$(\mathrm{e} 2)^{\prime \prime \prime}(f, g)$ is compatible pair.

On setting $\varphi(t)=\alpha t$ with $\alpha \in[0,1)$, in Theorem 1 (also in Theorem 2 or Theorem 3), we get the following result:

Corollary 3 Theorem 1 (also Theorem 2 or Theorem 3 ) remains true if we replace condition (d) by the following condition (besides retaining the rest of the hypotheses):

(d)' there exists $\alpha \in[0,1)$ such that

$$
d(f x, f y) \leq \alpha d(g x, g y) \quad \forall x, y \in X \text { with } g(x) \prec \succ g(y) .
$$

On setting $g=I$, the identity mapping on $X$, in Theorems 1,2 , and 3 , we get, respectively, the following corresponding fixed point results.

Corollary 4 Let $(X, d, \preceq)$ be an ordered metric space and $f$ a self mapping on $X$. Suppose that the following conditions hold: 
(a) either $(f X, d)$ or $(X, d)$ is complete,

(b) $f$ is increasing,

(c) either $f$ is continuous or $(X, d, \preceq)$ has the ICU property,

(d) there exists $x_{0} \in X$ such that $x_{0} \preceq f\left(x_{0}\right)$,

(e) there exists $\varphi \in \Omega$ such that

$$
d(f x, f y) \leq \varphi(d(x, y)) \quad \forall x, y \in X \text { with } x \prec \succ y .
$$

Then $f$ has a fixed point.

Notice that Corollary 4 improves Theorem 2.1 of Wu and Liu [17]. Here it is mentioned that in Theorem 2.1 of [17], the authors used $\Phi$ instead of $\Omega$ besides (in view of hypothesis (a)) the completeness of $X$.

Corollary 5 Corollary 4 remains true if the conditions (c) and (d) are replaced by the conditions $(\mathrm{c})^{\prime}$ and $(\mathrm{d})^{\prime}$, respectively (besides retaining the rest of the hypotheses):

(c)' either $f$ is continuous or $(X, d, \preceq)$ has the DCL property,

(d)' there exists $x_{0} \in X$ such that $x_{0} \succeq f\left(x_{0}\right)$.

Corollary 6 Corollary 4 remains true if the conditions (c) and (d) are replaced by the conditions (c)" and $(\mathrm{d})^{\prime \prime}$, respectively (besides retaining the rest of the hypotheses):

(c)" either $f$ is continuous or $(X, d, \preceq)$ has the MCB property,

(d)" there exists $x_{0} \in X$ such that $x_{0} \prec \succ f\left(x_{0}\right)$.

On setting $\varphi(t)=\alpha t$ with $\alpha \in[0,1)$, in Corollary 4 (also in Corollary 5 or Corollary 6 ), we get respectively the following results.

Corollary 7 Corollary 4 (also Corollary 5 or Corollary 6) remains true if the condition (e) is replaced by the following condition (besides retaining the rest of the hypotheses):

(e)' there exists $\alpha \in[0,1)$ such that

$$
d(f x, f y) \leq \alpha d(x, y) \quad \forall x, y \in X \text { with } x \prec \succ y .
$$

Notice that Corollary 7 covers Theorems 2.1, 2.2, and 2.4 of Nieto and Rodríguez-López [2]. Here we observe that in Nieto and Rodríguez-López's theorems the completeness of $X$ is not necessary, it can alternately be replaced by the completeness of $f(X)$.

Now, we make some observations on several well-known results in ordered metric spaces available in the existing literature.

The following result of Radenović [29] is a consequence of Theorem 1.

Corollary 8 (Radenović [29]) Let $(X, d, \preceq)$ be an ordered metric space and $f$ and $g$ two self mappings on $X$. Assume that there exists $\varphi \in \Phi$ such that

$$
d(f x, f y) \leq \varphi(d(g x, g y)) \quad \forall x, y \in X \text { with } g(x) \preceq g(y) \text { or } g(x) \succeq g(y) .
$$


(i) $f$ is $g$-increasing and $f(X) \subseteq g(X)$,

(ii) there exists $x_{0} \in X$ such that $g\left(x_{0}\right) \preceq f\left(x_{0}\right)$,

(iii) $f$ and $g$ are continuous and compatible and $(X, d)$ is complete, or

(iv) $(X, d, \preceq)$ has the $M C B$ property and one of $f(X)$ or $g(X)$ is complete.

Then $f$ and $g$ have a coincidence point.

Here, it can be pointed out that Radenović [29] call $X$ to be regular instead of saying that $X$ has $M C B$ property. On taking $\Phi$ instead of $\Omega$ and compatibility instead of $O$-compatibility in Theorem 1, we obtain a sharpened version of Corollary 8 which are worth noting in the following respects:

- In the context of hypothesis (iii), the continuity of $f$ is not necessary as it can alternately be replaced by the condition that $(X, d, \preceq)$ has the $g$-ICU property.

- In the context of hypothesis (iv), there is no point to use the $M C B$ property on $X$ as a relatively lighter $I C U$ property can serve the desired purpose (see lines 38 and 39 on p.370 in [29]). Moreover, there is no need to take the ICU property on the whole space $X$, it suffices to take it merely on $g(X)$. Also this condition (i.e. the $I C U$ property of $g(X))$ is not necessary as it can alternately be replaced by continuity requirements on $f$ and $g$ both.

The following result of Al-Mezel et al. [30] is a consequence of Theorem 1 and Corollary 1.

Corollary 9 (Al-Mezel et al. [30]) Let $(X, d, \preceq$ ) be an ordered metric space and $f, g: X \rightarrow X$ two mappings such that the following properties are fulfilled:

(i) $f(X) \subseteq g(X)$,

(ii) $f$ is $g$-increasing,

(iii) there exists $x_{0} \in X$ such that $g\left(x_{0}\right) \preceq f\left(x_{0}\right)$,

(iv) there exists $\varphi \in \Phi$ such that

$$
d(f x, f y) \leq \varphi(d(g x, g y)) \quad \forall x, y \in X \text { with } g(x) \preceq g(y) .
$$

Also assume that, at least, one of the following conditions holds:

(a) $(X, d)$ is complete, $f$ and $g$ are continuous and the pair $(f, g)$ is O-compatible,

(b) $(X, d)$ is complete and $f$ and $g$ are continuous and commuting,

(c) $(g X, d)$ is complete and $(X, d, \preceq)$ has the ICU property,

(d) $(X, d)$ is complete, $g(X)$ is closed and $(X, d, \preceq)$ has the ICU property,

(e) $(X, d)$ is complete, $g$ is continuous and increasing, the pair $(f, g)$ is O-compatible and $(X, d, \preceq)$ has the ICU property.

Then $f$ and $g$ have, at least, a coincidence point.

Notice that Al-Mezel et al. [30] call $X$ to be nondecreasing-regular instead of saying that $X$ has the $I C U$ property. On taking $\Phi$ instead of $\Omega$ in Theorem 1 (including Corollary 1 with assumptions $\left(f^{\prime}\right)$ and $\left.\left(f^{\prime \prime}\right)\right)$, we obtain a sharpened version of Corollary 9 which are worth noting in the following respects:

- In the context of hypotheses (a) and (b), the continuity of $f$ is not necessary as it can alternately be replaced by the condition that $(X, d, \preceq)$ has the $g$-ICU property.

- In the context of hypotheses (c) and (d), there is no need to take the ICU property on the whole space $X$, it suffices to take merely on $g(X)$. Also this condition (i.e. the $I C U$ 
property on $g(X))$ is not necessary as it can alternately be replaced by continuity requirements on both $f$ and $g$.

- In the context of hypothesis (c), the completeness of $g(X)$ is not necessary as it can alternately be replaced by the completeness of $f(X)$.

- In the context of hypothesis $(\mathrm{d})$, the closedness of $g(X)$ is not necessary as it can alternately be replaced by closedness of $f(X)$.

- In the context of hypothesis (e), it is clear that increasing requirement on $g$ together with the ICU property implies the $g$-ICU property, therefore it is more natural to use the $g$-ICU property as opposed to the $I C U$ property together with increasing requirement on $g$.

The following consequence of Corollary 1 is a special case of Theorem 2.2 of Ćirić et al. [6].

Corollary 10 Let $(X, d, \preceq)$ be an ordered metric space and $f$ and $g$ two self mappings on $X$. Suppose that the following conditions hold:

(i) $(X, d)$ is complete,

(ii) $g(X)$ is closed,

(iii) $f(X) \subseteq g(X)$,

(iv) $f$ is $g$-increasing,

(v) $(g X, d, \preceq)$ has the ICU property,

(vi) there exists $x_{0} \in X$ such that $g\left(x_{0}\right) \preceq f\left(x_{0}\right)$,

(vii) there exists $\varphi \in \Im$ such that

$$
d(f x, f y) \leq \varphi(d(g x, g y)) \quad \forall x, y \in X \text { with } g(x) \geq g(y) .
$$

Then $f$ and $g$ have a coincidence point.

Notice that in Theorem 2.2 of [6], Ćirić et al. used the following contractive condition instead of (vii), which is more general,

$$
d(f x, f y) \leq \max \left\{\varphi(d(g x, g y)), \varphi(d(g x, f x)), \varphi(d(g y, f y)), \varphi\left(\frac{d(g x, f y)+d(g y, f x)}{2}\right)\right\}
$$

$\forall x, y \in X$ with $g(x) \succeq g(y)$. On taking $\Im$ instead of $\Omega$ in Corollary 1 (with assumption ( $\mathrm{f}^{\prime}$ ) only), we obtain an improved version of Corollary 10, which are worth noting in the following considerations:

- In the context of hypothesis (ii), the closedness of $g(X)$ is not necessary as it can alternately be replaced by the closedness of $f(X)$.

- In the context of hypothesis (v), the ICU property on $g(X)$ is not necessary as it can alternately be replaced by continuity requirements on $f$ and $g$ both.

The following result of Dalal et al. [31] (with correction) is a consequence of Corollary 2.

Corollary 11 (Dalal et al. [31]) Let $(X, d, \preceq)$ be an ordered metric space and $f, g: X \rightarrow X$ two mappings satisfying the following:

(i) $f$ is $g$-increasing and $f(X) \subseteq g(X)$,

(ii) $g$ is continuous and commutes with $f$, 
(iii) there exists $x_{0} \in X$ such that $g\left(x_{0}\right) \preceq f\left(x_{0}\right)$, (iv) there exists $\varphi \in \Phi$ such that

$$
d(f x, f y) \leq \varphi(d(g x, g y)) \quad \forall x, y \in X \text { with } g(x) \preceq g(y) \text { or } g(x) \succeq g(y) .
$$

Also, suppose that either

(a) $f$ is continuous, or

(b) $(X, d, \preceq)$ has the $M C B$ property.

Then $f$ and $g$ have a coincidence point.

Notice that Dalal et al. [31] use the term sequential monotone property instead of the $M C B$ property. Firstly, we point out that Dalal et al. [31] used the completeness of $X$ in their proof but failed to mention the same in the hypotheses. Also, owing to the $M C B$ property on $X$, Dalal et al. [31] observed that $g\left(x_{n}\right) \preceq z$ (see line 14 on p.1092) which can not ensure the comparability of $g\left(g x_{n}\right)$ and $g(z)$. But Dalal et al. [31] used the same while writing $d\left(f g x_{n}, f z\right) \leq \varphi\left(d\left(g g x_{n}, g z\right)\right)$ (see lines 17 and 18 on p.1092 in Dalal et al. [31]). Hence, one needs to replace the $M C B$ property by the $g-I C U$ property which ensures that $g\left(g x_{n}\right) \preceq g(z)$, so that the given proof can work. Thus Corollary 11 contains some errors and omissions. In fact on taking $\Phi$ instead of $\Omega$ in Corollary 2 (with assumption (e2)' only), we obtain correct form of Corollary 11.

Now, as an application of Theorem 1, using the techniques of Samet et al. [28], one can easily obtain the following coupled coincidence theorem, which is indeed the coupled formulation of Theorem 1.

Theorem 4 Let $(X, d, \preceq)$ be an ordered metric space and $F: X^{2} \rightarrow X$ and $g: X \rightarrow X$ two mappings. Suppose that the following conditions hold:

(a) $F\left(X^{2}\right) \subseteq g(X)$,

(b) F has the mixed g-monotone property,

(c) there exist $x_{0}, y_{0} \in X$ such that $g\left(x_{0}\right) \preceq F\left(x_{0}, y_{0}\right)$ and $g\left(y_{0}\right) \succeq F\left(y_{0}, x_{0}\right)$,

(d) there exists $\varphi \in \Omega$ such that

$$
d(F(x, y), F(u, v)) \leq \varphi\left(\frac{d(g x, g u)+d(g y, g v)}{2}\right)
$$

$\forall x, y, u, v \in X$ with $g(x) \preceq g(u)$ and $g(y) \succeq g(v)$,

(e) (e1) $(X, d)$ is complete,

(e2) $(F, g)$ is O-compatible pair,

(e3) $g$ is continuous,

(e4) either $F$ is continuous or $(X, d, \preceq)$ has the $g$-MCB property,

or alternately

$\left(\mathrm{e}^{\prime}\right)\left(\mathrm{e}^{\prime} 1\right)$ either $(g X, d)$ or $\left(F X^{2}, d\right)$ is complete,

$\left(e^{\prime} 2\right)$ either $F$ and $g$ are continuous or $(g X, d, \preceq)$ has the MCB property.

Then $F$ and $g$ have a coincidence point.

The following two coupled coincidence theorems directly follow from Theorem 4 . 
Corollary 12 (Choudhury and Kundu [21]) Let $(X, d, \preceq)$ be an ordered metric space and $F: X^{2} \rightarrow X$ and $g: X \rightarrow X$ two mappings. Suppose that the following conditions hold:

(i) $(X, d)$ is complete,

(ii) $F\left(X^{2}\right) \subseteq g(X)$,

(iii) $F$ has the mixed g-monotone property,

(iv) $(F, g)$ is a compatible pair,

(v) $g$ is continuous and increasing,

(vi) either $F$ is continuous or $(X, d, \preceq)$ has the MCB property,

(vii) there exist $x_{0}, y_{0} \in X$ such that $g\left(x_{0}\right) \preceq F\left(x_{0}, y_{0}\right)$ and $g\left(y_{0}\right) \succeq F\left(y_{0}, x_{0}\right)$,

(viii) there exists $\varphi \in \Phi$ such that

$$
\begin{array}{r}
d(F(x, y), F(u, v)) \leq \varphi\left(\frac{d(g x, g u)+d(g y, g v)}{2}\right) \\
\forall x, y, u, v \in X \text { with } g(x) \preceq g(u) \text { and } g(y) \succeq g(v) .
\end{array}
$$

Then $F$ and $g$ have a coupled coincidence point

On taking $\Phi$ instead of $\Omega$ and compatibility instead of $O$-compatibility in Theorem 4 (with assumption (e) only), we obtain a sharpened version of Corollary 12. Notice that there is no need of increasing requirement on $g$ in Corollary 12 if $F$ is continuous and this property is used only when $X$ has $M C B$ property. As the requirement of increasing on $g$ together with the $M C B$ property implies $g-M C B$ property, it is more natural to use the $g-M C B$ property as opposed to the $M C B$ property together with the requirement of increasing on $g$.

Corollary 13 (Husain et al. [22], Sintunavarat and Kumam [23]) Let $(X, d, \preceq)$ be an ordered metric space and $F: X^{2} \rightarrow X$ and $g: X \rightarrow X$ two mappings. Suppose that the following conditions hold:

(i) $(g X, d)$ is complete,

(ii) $F\left(X^{2}\right) \subseteq g(X)$,

(iii) $F$ has the mixed $g$-monotone property,

(iv) $g$ is continuous,

(v) either $F$ is continuous or $(X, d, \preceq)$ has the MCB property,

(vi) there exist $x_{0}, y_{0} \in X$ such that $g\left(x_{0}\right) \preceq F\left(x_{0}, y_{0}\right)$ and $g\left(y_{0}\right) \succeq F\left(y_{0}, x_{0}\right)$,

(vii) there exists $\varphi \in \Phi$ such that

$$
\begin{aligned}
d(F(x, y), F(u, v)) & \leq \varphi\left(\frac{d(g x, g u)+d(g y, g v)}{2}\right) \\
\forall x, y, u, v \in X \text { with } g(x) & \preceq g(u) \text { and } g(y) \succeq g(v) .
\end{aligned}
$$

Then $F$ and $g$ have a coupled coincidence point.

On taking $\Phi$ instead of $\Omega$ in Theorem 4 (with assumption ( $\left.\mathrm{e}^{\prime}\right)$ only), we obtain a sharpened version of Corollary 13, for which it is worth noting in following features:

- In the context of hypothesis (i), the completeness of $g(X)$ is not necessary as it can alternately be replaced by the completeness of $F\left(X^{2}\right)$.

- In the context of hypothesis (v), there is no need to take the $M C B$ property on the whole space $X$, it suffices to take it merely on $g(X)$. 
- In the context of hypotheses (iv) and (v), the continuity of $g$ is unnecessary, when the $M C B$ property on $g(X)$ holds. It is required only when $F$ is continuous.

\section{Uniqueness results}

In this section, we state and prove the results regarding the uniqueness of a point of coincidence, coincidence point and common fixed point corresponding to previous results. For a pair of self mappings $f$ and $g$ on a nonempty set $X$, we denote the following sets:

$\mathrm{C}(f, g)=\{x \in X: g x=f x\}$, i.e., the set of all coincidence points of $f$ and $g$,

$\overline{\mathrm{C}}(f, g)=\{\bar{x} \in X: \bar{x}=g x=f x, x \in X\}$, i.e., the set of all points of coincidence of $f$ and $g$.

Theorem 5 In addition to the hypotheses (a)-(d) along with ( $\left.\mathrm{e}^{\prime}\right)$ of Theorem 1 (resp. Theorem 2 or Theorem 3), if the following condition holds:

$\left(\mathrm{u}_{0}\right):$ for all $x, y \in X, \exists z \in X$ such that $g(x) \prec \succ g(z)$ and $g(y) \prec \succ g(z)$,

then $f$ and $g$ have a unique point of coincidence.

Proof We prove this result for Theorem 1 and the same argument holds for others. In view of Theorem $1, \overline{\mathrm{C}}(f, g) \neq \emptyset$. Take $\bar{x}, \bar{y} \in \overline{\mathrm{C}}(f, g)$, then $\exists x, y \in X$ such that

$$
\bar{x}=g(x)=f(x) \quad \text { and } \quad \bar{y}=g(y)=f(y) .
$$

We show that $\bar{x}=\bar{y}$. According to assumption $\left(\mathrm{u}_{0}\right), \exists z \in X$ such that $g(x) \prec \succ g(z)$ and $g(y) \prec \succ g(z)$, i.e., either $g(x) \preceq g(z)$ or $g(x) \succeq g(z)$ and the same argument will be true for $g(y)$ and $g(z)$. We can suppose $g(x) \preceq g(z)$ (the other case is similar). Put $z_{0}=z$. Since $f(X) \subseteq g(X)$, along lines similar to that of Theorem 1, we can define sequence $\left\{z_{n}\right\} \subset X$ such that

$$
g\left(z_{n+1}\right)=f\left(z_{n}\right) .
$$

Again as $f$ is $g$-increasing, by a similar reason as in the proof of Theorem 1, we have

$$
g\left(z_{n}\right) \preceq g\left(z_{n+1}\right) \quad \forall n \in \mathbb{N} \cup\{0\} .
$$

Hence on using $g(x) \preceq g\left(z_{0}\right)$, we have

$$
g(x) \preceq g\left(z_{n}\right) \quad \forall n \in \mathbb{N} \cup\{0\} .
$$

Now we claim that

$$
\lim _{n \rightarrow \infty} d\left(g x, g z_{n}\right)=0
$$

For each $n \in \mathbb{N} \cup\{0\}$, define

$$
t_{n}:=d\left(g x, g z_{n}\right)
$$

Now two cases arise. Firstly, suppose that $t_{n_{0}}=d\left(g x, g z_{n_{0}}\right)=0$ for some $n_{0} \in \mathbb{N} \cup\{0\}$, then by Proposition 1, we obtain $d\left(f x, f z_{n_{0}}\right)=0$. Consequently on using (27) and (28), we get 
$t_{n_{0}+1}=d\left(g x, g z_{n_{0}+1}\right)=d\left(f x, f z_{n_{0}}\right)=0$. Thus by induction, we get $t_{n}=0 \forall n \geq n_{0}$, yielding thereby $\lim _{n \rightarrow \infty} t_{n}=0$. Hence, in this case, (30) is proved.

On the other hand suppose that $t_{n}>0 \forall n \in \mathbb{N} \cup\{0\}$, then on using (27), (28), (29), (31), and assumption (d), we have

$$
\begin{aligned}
t_{n+1} & =d\left(g x, g z_{n+1}\right) \\
& =d\left(f x, f z_{n}\right) \\
& \leq \varphi\left(d\left(g x, g z_{n}\right)\right) \\
& =\varphi\left(t_{n}\right),
\end{aligned}
$$

so that

$$
t_{n+1} \leq \varphi\left(t_{n}\right)
$$

Hence on applying Lemma 3 , we obtain $\lim _{n \rightarrow \infty} t_{n}=0$, so that (30) is proved. Thus, in both cases, (30) holds. Similarly, one can show that

$$
\lim _{n \rightarrow \infty} d\left(g y, g z_{n}\right)=0 .
$$

On using triangular inequality, (30) and (32), we obtain

$$
\begin{aligned}
& d(\bar{x}, \bar{y})=d(g x, g y) \leq d\left(g x, g z_{n}\right)+d\left(g z_{n}, g y\right) \rightarrow 0 \quad \text { as } n \rightarrow \infty \\
& \Longrightarrow \quad \bar{x}=\bar{y} .
\end{aligned}
$$

Thus, $f$ and $g$ have a unique point of coincidence.

Corollary 14 Theorem 5 remains true if we replace the condition $\left(u_{0}\right)$ by one of the following conditions (besides retaining rest of the hypotheses):

$\left(\mathrm{u}_{0}^{1}\right)$ : for all $x, y \in X, \exists z \in X$ such that $g(x) \prec \succ f(z)$ and $g(y) \prec \succ f(z)$,

$\left(\mathrm{u}_{0}^{2}\right)$ : for all $x, y \in X, \exists z \in X$ such that $f(x) \prec \succ g(z)$ and $f(y) \prec \succ g(z)$,

$\left(\mathrm{u}_{0}^{3}\right)$ : for all $x, y \in X, \exists z \in X$ such that $f(x) \prec \succ f(z)$ and $f(y) \prec \succ f(z)$,

$\left(\mathrm{u}_{0}^{4}\right)$ : every pair of elements of $g(X)$ has a lower bound or an upper bound in $g(X)$,

$\left(\mathrm{u}_{0}^{5}\right)$ : every pair of elements of $f(X)$ has a lower bound or an upper bound in $g(X)$,

$\left(\mathrm{u}_{0}^{6}\right)$ : every pair of elements of $f(X)$ has a lower bound or an upper bound in $f(X)$,

$\left(\mathrm{u}_{0}^{7}\right):(f X, \preceq)$ is totally ordered,

$\left(\mathbf{u}_{0}^{8}\right):(g X, \preceq)$ is totally ordered,

$\left(\mathrm{u}_{0}^{9}\right):(X, \preceq)$ is totally ordered.

Proof As $f(X) \subseteq g(X)$, for $x, y, z \in X \exists u, v, w \in X$ such that $f(x)=g(u), f(y)=g(v), f(z)=$ $g(w)$. Hence, we have

$$
\begin{aligned}
& \left(\mathrm{u}_{0}^{1}\right) \Rightarrow g(x) \prec \succ f(z)=g(w), g(y) \prec \succ f(z)=g(w), \\
& \left(\mathrm{u}_{0}^{2}\right) \Rightarrow g(u)=f(x) \prec \succ g(z), g(v)=f(y) \prec \succ g(z), \\
& \left(\mathrm{u}_{0}^{3}\right) \Rightarrow g(u)=f(x) \prec \succ f(z)=g(w), g(v)=f(y) \prec \succ f(z)=g(w),
\end{aligned}
$$

which amounts to saying that, in each case, $\left(\mathrm{u}_{0}\right)$ holds and hence Theorem 5 is applicable. 
It is easy to check that $\left(\mathrm{u}_{0}^{4}\right) \Rightarrow\left(\mathrm{u}_{0}^{5}\right),\left(\mathrm{u}_{0}^{6}\right) \Rightarrow\left(\mathrm{u}_{0}^{5}\right),\left(\mathrm{u}_{0}^{5}\right) \Rightarrow\left(\mathrm{u}_{0}^{2}\right)$, so that the results follow due to availability of the result under condition $\left(u_{0}^{2}\right)$.

Again, $\left(\mathrm{u}_{0}^{9}\right) \Rightarrow\left(\mathrm{u}_{0}^{8}\right) \Rightarrow\left(\mathrm{u}_{0}^{7}\right) \Rightarrow\left(\mathrm{u}_{0}^{3}\right)$ and hence such results follow due to availability of the result corresponding to $\left(u_{0}^{3}\right)$.

Theorem 6 In addition to the hypotheses of Theorem 5, if the following condition holds:

$\left(\mathrm{u}_{1}\right)$ : one off and $g$ is one-one,

then $f$ and $g$ have a unique coincidence point.

Proof In view of Theorem $1, \mathrm{C}(f, g) \neq \emptyset$. Take $x, y \in \mathrm{C}(f, g)$, then in view of Theorem 5 , we have

$$
g(x)=f(x)=f(y)=g(y) .
$$

As $f$ or $g$ is one-one, we have

$$
x=y .
$$

Theorem 7 In addition to the hypotheses of Theorem 5, if the following condition holds:

$\left(\mathrm{u}_{2}\right):(f, g)$ is weakly compatible pair,

then $f$ and $g$ have a unique common fixed point.

Proof Take $x \in \mathrm{C}(f, g)$ and denote $g(x)=f(x)=\bar{x}$. Then in view of Proposition 2 and $\left(\mathrm{u}_{2}\right)$, $\bar{x} \in C(f, g)$. It follows from Theorem 5 with $y=\bar{x}$ that $g(x)=g(\bar{x})$, i.e., $\bar{x}=g(\bar{x})$, which yields

$$
\bar{x}=g(\bar{x})=f(\bar{x}) .
$$

Hence, $\bar{x}$ is a common fixed point of $f$ and $g$. To prove uniqueness, assume that $x^{*}$ is another common fixed point of $f$ and $g$. Then again from Theorem 5 , we have

$$
x^{*}=g\left(x^{*}\right)=g(\bar{x})=\bar{x} .
$$

Hence we are through.

Theorem 8 In addition to the hypotheses (a)-(e) of Theorem 1 (resp. Theorem 2 or Theorem 3 ), if the condition $\left(\mathrm{u}_{0}\right)$ (of Theorem 5 ) holds, then $f$ and $g$ have a unique common fixed point.

Proof We know that in an ordered metric space, every $O$-compatible pair is weakly compatible, so that $\left(\mathrm{u}_{2}\right)$ trivially holds. Hence similar to the lines of proof of Theorems 5 and 7 our result follows.

Theorem 8 asserts that assumption $\left(\mathrm{u}_{0}\right)$ together with Corollary 2 provides the uniqueness of common fixed point.

Remark 3 Theorem 8 remains true if condition $\left(\mathrm{u}_{0}\right)$ is replaced by any one of the conditions $\left(\mathrm{u}_{0}^{1}\right)-\left(\mathrm{u}_{0}^{9}\right)$ (of Corollary 14$)$ besides retaining rest of the hypotheses. 
Remark 4 If the sets $C(f, g)$ and $\bar{C}(f, g)$ are known then in view of the proofs of Theorem 5 , Theorem 8 and Corollary 14 , it is clear that $\left(\mathrm{u}_{0}\right)$ can be replaced by one of the following conditions, which are relatively weaker than the assumptions mentioned in these results:

$\left(\overline{\mathrm{u}}_{0}^{1}\right)$ : for all $x, y \in \mathrm{C}(f, g), \exists z \in X$ such that $f(x)=g(x) \prec \succ g(z)$ and $f(y)=g(y) \prec \succ g(z)$, $\left(\overline{\mathrm{u}}_{0}^{2}\right)$ : for all $x, y \in \mathrm{C}(f, g), \exists z \in X$ such that $g(x)=f(x) \prec \succ f(z)$ and $g(y)=f(y) \prec \succ f(z)$, $\left(\overline{\mathrm{u}}_{0}^{3}\right)$ : every pair of elements of $\overline{\mathrm{C}}(f, g)$ has a lower bound or an upper bound in $g(X)$, $\left(\overline{\mathrm{u}}_{0}^{4}\right)$ : every pair of elements of $\overline{\mathrm{C}}(f, g)$ has a lower bound or an upper bound in $f(X)$, $\left(\overline{\mathrm{u}}_{0}^{5}\right): \overline{\mathrm{C}}(f, g)$ is totally ordered set with respect to $\preceq$.

Remark 5 Under the arguments of Remark 4, one can replace assumption $\left(\mathrm{u}_{1}\right)$ (of Theorem 6) by the following condition, which is weaker:

$\left(\overline{\mathrm{u}}_{1}\right): g=f: \mathrm{C}(f, g) \rightarrow \overline{\mathrm{C}}(f, g)$ is a bijection.

By setting $g=I$ (the identity mapping on $X$ ) in Theorems 5-8, we deduce the following unique fixed point results, which are indeed the uniqueness results corresponding to Corollaries 4-7.

Corollary 15 In addition to the hypotheses of Corollary 4 (resp. Corollary 5, Corollary 6 or Corollary 7), if one of the following conditions holds:

$\left(\mathrm{u}_{1}^{\prime}\right):$ for all $x, y \in X$, there exists $z \in X$ such that $x \prec \succ z$ and $y \prec \succ z$,

$\left(\mathrm{u}_{2}^{\prime}\right)$ : for all $x, y \in X, \exists z \in X$ such that $x \prec \succ f(z)$ and $y \prec \succ f(z)$,

$\left(\mathrm{u}_{3}^{\prime}\right)$ : for all $x, y \in X, \exists z \in X$ such that $f(x) \prec \succ z$ and $f(y) \prec \succ z$,

$\left(\mathrm{u}_{4}^{\prime}\right)$ : for all $x, y \in X, \exists z \in X$ such that $f(x) \prec \succ f(z)$ and $f(y) \prec \succ f(z)$,

$\left(\mathrm{u}_{5}^{\prime}\right)$ : every pair of elements of $X$ has a lower bound or an upper bound,

$\left(\mathrm{u}_{6}^{\prime}\right)$ : every pair of elements of $f(X)$ has a lower bound or an upper bound,

$\left(u_{7}^{\prime}\right):(f X, \preceq)$ is totally ordered,

$\left(\mathrm{u}_{8}^{\prime}\right):(X, \preceq)$ is totally ordered,

then $f$ has a unique fixed point.

\section{Examples}

In this section, we furnish two examples, which illustrate Theorem 1 and Theorems 5-8.

Example 5 Let $X=\mathbb{R}$. Then $(X, d, \preceq)$ is an ordered metric space under the usual metric and the partial order defined by $x \preceq y \Leftrightarrow|x| \leq|y|$ and $x y \geq 0$. Define $f: X \rightarrow X$ and $g: X \rightarrow$ $X$ by $f(x)=\frac{x^{2}}{5}$ and $g(x)=\frac{x^{2}}{3} \forall x \in X$. Then $f$ is $g$-increasing. Define $\varphi:[0, \infty) \rightarrow[0, \infty)$ by $\varphi(t)=\frac{7 t}{9} \forall t \in[0, \infty)$, then $\varphi \in \Omega$. Now, for $x, y \in X$ with $g(x) \preceq g(y)$, we have

$$
d(f x, f y)=\left|\frac{x^{2}}{5}-\frac{y^{2}}{5}\right|=\frac{3}{5}\left|\frac{x^{2}}{3}-\frac{y^{2}}{3}\right|=\frac{3}{5} d(g x, g y)<\frac{7}{9} d(g x, g y)=\varphi(d(g x, g y)) .
$$

Thus $f, g$ and $\varphi$ satisfy assumption (d) of Theorem 1. By a routine calculation, one can verify all the conditions mentioned in (e) of Theorem 1 . Hence all the conditions of Theorem 1 are satisfied and $f$ and $g$ have a coincidence point in $X$. Moreover, here $\left(\mathrm{u}_{0}\right)$ holds and therefore, in view of Theorem $8, f$ and $g$ have a unique common fixed point (namely: $x=0)$. 
Example 6 Consider $X=\mathbb{R}$ with the usual metric and the usual order. Then $(X, d, \preceq)$ is an ordered metric space. Define $f: X \rightarrow X$ and $g: X \rightarrow X$ by $f(x)=1$ and $g(x)=x^{2}-8$ $\forall x \in X$. Then $f$ is $g$-increasing. Define $\varphi:[0, \infty) \rightarrow[0, \infty)$ by $\varphi(t)=\alpha t \forall t \in[0, \infty)$, where $\alpha \in[0,1)$, then $\varphi \in \Omega$. Now, for $x, y \in X$ with $g(x) \preceq g(y)$, we have

$$
d(f x, f y)=|1-1|=0 \leq \alpha\left|x^{2}-y^{2}\right|=\alpha d(g x, g y)=\varphi(d(g x, g y)) .
$$

Thus $f, g$ and $\varphi$ satisfy assumption (d) of Theorem 1 . Also, the pair $(f, g)$ is not $O$-compatible and hence (e) does not hold. But the subspace $g(X)=[-8, \infty)$ is complete and $f$ and $g$ are continuous, i.e., all the conditions mentioned in $\left(e^{\prime}\right)$ are satisfied. Hence by Theorem $1, f$ and $g$ have a coincidence point in $X$. Further, in this example $\left(\mathrm{u}_{0}\right)$ holds and therefore, in view of Theorem 5, $f$ and $g$ have a unique point of coincidence (namely: $\bar{x}=1)$. Notice that neither $f$ nor $g$ is one-one, i.e., $\left(\mathrm{u}_{1}\right)$ does not hold and hence, we cannot apply Theorem 6 , which guarantees the uniqueness of coincidence point. Notice that there are two coincidence points (namely: $x=3$ and $x=-3$ ). Also, the pair $(f, g)$ is not weakly compatible, i.e., $\left(\mathrm{u}_{2}\right)$ does not hold and, hence, we cannot apply Theorem 7 , which ensures the uniqueness of common fixed point. Notice that there is no common fixed point of $f$ and $g$.

\section{Competing interests}

The authors declare that there is no conflict of interests.

\section{Authors' contributions}

All the authors discussed the entire text and are unanimous on the final draft of this research article. Thus formally, all the authors read and approved the final manuscript.

\section{Author details}

${ }^{1}$ Department of Mathematics, Aligarh Muslim University, Aligarh, 202002, India. ${ }^{2}$ Department of Mathematics, College of Science, Jazan University, Jazan, Kingdom of Saudi Arabia.

\section{Acknowledgements}

All the authors are grateful to three learned referees for their critical readings and pertinent comments on the earlier version of the manuscript.

Received: 8 July 2014 Accepted: 26 September 2014 Published: 22 Oct 2014

\section{References}

1. Ran, ACM, Reurings, MCB: A fixed point theorem in partially ordered sets and some applications to matrix equations. Proc. Am. Math. Soc. 132(5), 1435-1443 (2004)

2. Nieto, JJ, Rodríguez-López, R: Contractive mapping theorems in partially ordered sets and applications to ordinary differential equations. Order 22(3), 223-239 (2005)

3. Nieto, JJ, Rodríguez-López, R: Existence and uniqueness of fixed point in partially ordered sets and applications to ordinary differential equation. Acta Math. Sin. Engl. Ser. 23(12), 2205-2212 (2007)

4. Agarwal, RP, El-Gebeily, MA, O’Regan, D: Generalized contractions in partially ordered metric spaces. Appl. Anal. 87(1), 109-116 (2008)

5. O'Regan, D, Petrusel, A: Fixed point theorems for generalized contractions in ordered metric spaces. J. Math. Anal. Appl. 341(2), 1241-1252 (2008)

6. Ćirić, L, Cakić, N, Rajović, M, Ume, JS: Monotone generalized nonlinear contractions in partially ordered metric spaces. Fixed Point Theory Appl. 2008, Article ID 131294 (2008)

7. Harjani, J, Sadarangani, K: Fixed point theorems for weakly contractive mappings in partially ordered sets. Nonlinear Anal. 71(7-8), 3403-3410 (2009)

8. Harandi, AA, Emami, H: A fixed point theorem for contraction type maps in partially ordered metric spaces and application to ordinary differential equations. Nonlinear Anal. 72(5), 2238-2242 (2010)

9. Harjani, J, Sadarangani, K: Generalized contractions in partially ordered metric spaces and applications to ordinary differential equations. Nonlinear Anal. 72, 1188-1197 (2010)

10. Altun, I, Simsek, H: Some fixed point theorems on ordered metric spaces and application. Fixed Point Theory Appl. 2010, Article ID 621469 (2010)

11. Caballero, J, Harjani, J, Sadarangani, K: Contractive-like mapping principles in ordered metric spaces and application to ordinary differential equations. Fixed Point Theory Appl. 2010, Article ID 916064 (2010) 
12. Jachymski, J: Equivalent conditions for generalized contractions on (ordered) metric spaces. Nonlinear Anal. 74(3), 768-774 (2011)

13. Turinici, M: Ran-Reurings fixed point results in ordered metric spaces. Libertas Math. 31, 49-55 (2011)

14. Turinici, M: Nieto-Lopez theorems in ordered metric spaces. Math. Stud. 81(1-4), 219-229 (2012)

15. Jleli, M, Rajić, VĆ, Samet, B, Vetro, C: Fixed point theorems on ordered metric spaces and applications to nonlinear elastic beam equations. J. Fixed Point Theory Appl. 12, 175-192 (2012)

16. Nashine, HK, Altun, I: A common fixed point theorem on ordered metric spaces. Bull. Iran. Math. Soc. 38(4), 925-934 (2012)

17. $\mathrm{Wu}, \mathrm{J}, \mathrm{Liu}, \mathrm{Y}$ : Fixed point theorems for monotone operators and applications to nonlinear elliptic problems. Fixed Point Theory Appl. 2013, 134 (2013)

18. Guo, D, Lakshmikantham, V: Coupled fixed points of nonlinear operators with applications. Nonlinear Anal. 11(5) 623-632 (1987)

19. Bhaskar, TG, Lakshmikantham, V: Fixed point theorems in partially ordered metric spaces and applications. Nonlinear Anal. 65(7), 1379-1393 (2006)

20. Lakshmikantham, V, Ćirić, L: Coupled fixed point theorems for nonlinear contractions in partially ordered metric spaces. Nonlinear Anal. 70, 4341-4349 (2009)

21. Choudhury, BS, Kundu, A: A coupled coincidence point result in partially ordered metric spaces for compatible mappings. Nonlinear Anal. 73, 2524-2531 (2010)

22. Hussain, N, Latif, A, Shah, MH: Coupled and tripled coincidence point results without compatibility. Fixed Point Theory Appl. 2012, 77 (2012)

23. Sintunavarat, W, Kumam, P: Coupled fixed point results for nonlinear integral equations. J. Egypt. Math. Soc. 21(3) 266-272 (2013)

24. Hung, NM, Karapinar, E, Luong, NV: Coupled coincidence point theorem in partially ordered metric spaces via implicit relation. Abstr. Appl. Anal. 2012, Article ID 796964 (2012)

25. Gülyaz, S, Karapinar, E, Yüce, IS: A coupled coincidence point theorem in partially ordered metric spaces with an implicit relation. Fixed Point Theory Appl. 2013, 38 (2013)

26. Chandok, S, Karapinar, E, Khan, MS: Existence and uniqueness of common coupled fixed point results via auxiliary functions. Bull. Iran. Math. Soc. 40(1), 199-215 (2014)

27. Alsulami, $\mathrm{HH}$, Karapinar, E, Roldan, A: Imperative remarks for on common coupled fixed point theorems and an answer to question: how to smooth away it. Abstr. Appl. Anal. 2014, Article ID 730268 (2014)

28. Samet, B, Karapinar, E, Aydi, H, Rajić, VĆ: Discussion on some coupled fixed point theorems. Fixed Point Theory Appl. 2013, 50 (2013)

29. Radenović, S: A note on tripled coincidence and tripled common fixed point theorems in partially ordered metric spaces. Appl. Math. Comput. 236, 367-372 (2014)

30. Al-Mezel, SA, Alsulami, HH, Karapinar, E, Roldan, A: Discussion on 'Multidimensional coincidence points' via recent publications. Abstr. Appl. Anal. 2014, Article ID 287492 (2014)

31. Dalal, S, Khan, LA, Masmali, I, Radenović, S: Some remarks on multidimensional fixed point theorems in partially ordered metric spaces. J. Adv. Math. 7(1), 1084-1094 (2014)

32. Carl, S, Heikkilä, S: Fixed Point Theory in Ordered Sets and Applications: From Differential and Integral Equations to Game Theory. Springer, New York (2011)

33. Rus, IA: Generalized Contractions and Applications. Cluj University Press, Cluj-Napoca (2001)

34. Matkowski, J: Integrable solutions of functional equations. Diss. Math. 127, 1-68 (1975)

35. Karapinar, E: Fixed point theory for cyclic weak $\phi$-contraction. Appl. Math. Lett. 24(6), 822-825 (2011)

36. Karapinar, E: Weak $\phi$-contraction on partial contraction. J. Comput. Anal. Appl. 14(2), 206-210 (2012)

37. Aydi, H, Karapinar, E: A Meir-Keeler common type fixed point theorem on partial metric spaces. Fixed Point Theory Appl. 2012, $26(2012)$

38. Karapinar, E: A note on common fixed point theorems in partial metric spaces. Miskolc Math. Notes 12(2), 185-191 (2011)

39. Aydi, H, Karapinar, E, Shatanawi, W: Tripled coincidence point results for generalized contractions in ordered generalized metric spaces. Fixed Point Theory Appl. 2012, 101 (2012)

40. Imdad, M, Kumar, S, Khan, MS: Remarks on some fixed point theorems satisfying implicit relations. Rad. Mat. 11(1) 135-143 (2002)

41. Boyd, DW, Wong, JSW: On nonlinear contractions. Proc. Am. Math. Soc. 20, 458-464 (1969)

42. Jotić, N: Some fixed point theorems in metric spaces. Indian J. Pure Appl. Math. 26, 947-952 (1995)

43. Browder, FE: On the convergence of successive approximations for nonlinear functional equations. Proc. K. Ned. Akad. Wet., Ser. A, Indag. Math. 30, 27-35 (1968)

44. Mukherjea, A: Contractions and completely continuous mappings. Nonlinear Anal. 1(3), 235-247 (1977)

45. Lipschutz, S: Schaum's Outlines of Theory and Problems of Set Theory and Related Topics. McGraw-Hill, New York (1964)

46. Tarski, A: A lattice-theoretical fixpoint theorem and its applications. Pac. J. Math. 5, 285-309 (1955)

47. Kurepa, D: Fixpoints of decreasing mappings of ordered sets. Publ. Inst. Math. (Belgr.) 18(32), 111-116 (1975)

48. DeMarr, R: Common fixed points for isotone mappings. Colloq. Math. 13, 45-48 (1964)

49. Wong, JSW: Common fixed points of commuting monotone mappings. Can. J. Math. 19, 617-620 (1967)

50. McShane, EJ: Order-Preserving Maps and Integration Processes. Ann. Math. St., vol. 31. Princeton University Press, Princeton (1953)

51. Björner, A: Order-reversing maps and unique fixed points in complete lattices. Algebra Univers. 12, $402-403$ (1981)

52. Turinici, M: Abstract comparison principles and multivariable Gronwall-Bellman inequalities. J. Math. Anal. Appl. 117(1), 100-127 (1986)

53. Jungck, G: Commuting maps and fixed points. Am. Math. Mon. 83(4), 261-263 (1976)

54. Jungck, G: Common fixed points for noncontinuous nonself maps on non-metric spaces. Far East J. Math. Sci. 4, 199-215 (1996)

55. Sessa, S: On a weak commutativity condition of mappings in fixed point considerations. Publ. Inst. Math. (Belgr.) 32 149-153 (1982) 
56. Jungck, G: Compatible mappings and common fixed points. Int. J. Math. Math. Sci. 9(4), 771-779 (1986)

57. Luong, NV, Thuan, NX: Coupled points in ordered generalized metric spaces and application to integro differential equations. An. Univ. 'Ovidius' Constanţa, Ser. Mat. 21(3), 155-180 (2013)

58. Turinici, M: Product fixed points in ordered metric spaces (2011). arXiv:1110.3079v1

59. Kutbi, MA, Roldan, A, Sintunavarat, W, Martinez-Moreno, J, Roldan, C: F-Closed sets and coupled fixed point theorems without the mixed monotone property. Fixed Point Theory Appl. 2013, 330 (2013)

60. Berzig, M, Samet, B: An extension of coupled fixed point's concept in higher dimension and applications. Comput. Math. Appl. 63(8), 1319-1334 (2012)

61. Roldan, A, Martinez-Moreno, J, Roldan, C: Multidimensional fixed point theorems in partially ordered complete metric spaces. J. Math. Anal. Appl. 396(2), 536-545 (2012)

62. Haghi, RH, Rezapour, S, Shahzad, N: Some fixed point generalizations are not real generalizations. Nonlinear Anal. 74, 1799-1803 (2011)

63. Banach, S: Sur les opérations dans les ensembles abstraits et leur application aux équations intégrales. Fundam. Math. 3, 133-181 (1922)

10.1186/1687-1812-2014-216

Cite this article as: Alam et al.: Some coincidence theorems for generalized nonlinear contractions in ordered metric spaces with applications. Fixed Point Theory and Applications 2014, 2014:216

\section{Submit your manuscript to a SpringerOpen ${ }^{\circ}$ journal and benefit from:}

- Convenient online submission

- Rigorous peer review

- Immediate publication on acceptance

- Open access: articles freely available online

- High visibility within the field

- Retaining the copyright to your article 